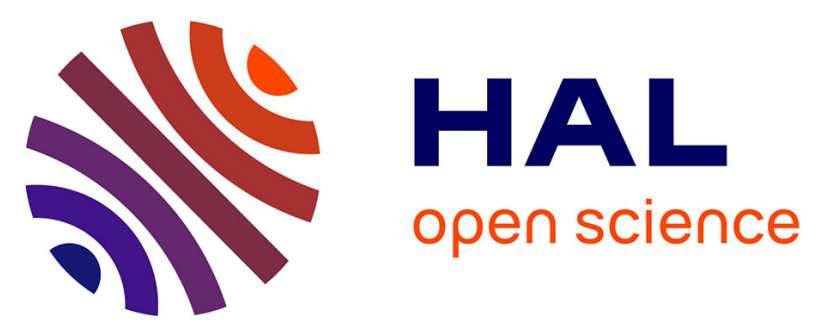

\title{
Efficient energy transfer from Si-nanoclusters to Er ions in silica induced by substrate heating during deposition
}

Sébastien Cueff, Christophe Labbé, Julien Cardin, Jean-Louis Doualan, Larysa Khomenkova, Khalil Hijazi, Olivier Jambois, B. Garrido, Richard Rizk

\section{- To cite this version:}

Sébastien Cueff, Christophe Labbé, Julien Cardin, Jean-Louis Doualan, Larysa Khomenkova, et al.. Efficient energy transfer from Si-nanoclusters to Er ions in silica induced by substrate heating during deposition. Journal of Applied Physics, 2010, 108 (6), pp.064302. 10.1063/1.3481375 . hal-01139770

\author{
HAL Id: hal-01139770 \\ https://hal.science/hal-01139770
}

Submitted on 7 Apr 2015

HAL is a multi-disciplinary open access archive for the deposit and dissemination of scientific research documents, whether they are published or not. The documents may come from teaching and research institutions in France or abroad, or from public or private research centers.
L'archive ouverte pluridisciplinaire HAL, est destinée au dépôt et à la diffusion de documents scientifiques de niveau recherche, publiés ou non, émanant des établissements d'enseignement et de recherche français ou étrangers, des laboratoires publics ou privés. 


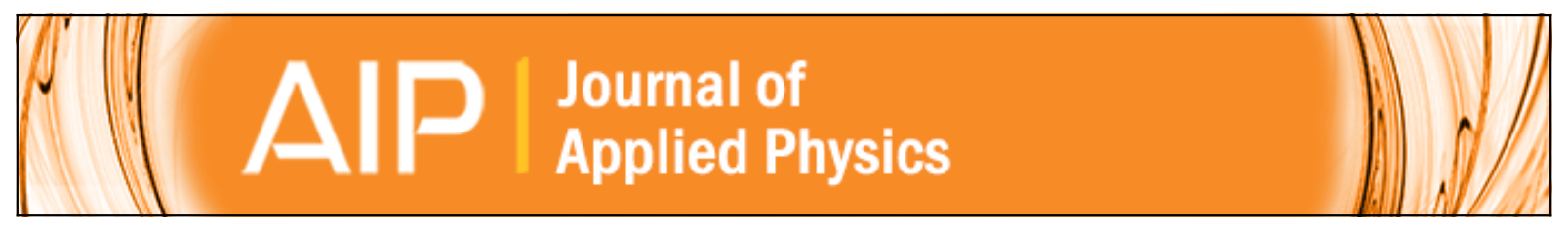

\section{Efficient energy transfer from Si-nanoclusters to Er ions in silica induced by substrate heating during deposition}

Sébastien Cueff, Christophe Labbé, Julien Cardin, Jean-Louis Doualan, Larysa Khomenkova, Khalil Hijazi, Olivier Jambois, Blas Garrido, and Richard Rizk

Citation: Journal of Applied Physics 108, 064302 (2010); doi: 10.1063/1.3481375

View online: http://dx.doi.org/10.1063/1.3481375

View Table of Contents: http://scitation.aip.org/content/aip/journal/jap/108/6?ver=pdfcov

Published by the AIP Publishing

\section{Articles you may be interested in}

Resonant structures based on amorphous silicon suboxide doped with $\operatorname{Er} 3+$ with silicon nanoclusters for an efficient emission at $1550 \mathrm{~nm}$

J. Vac. Sci. Technol. B 27, L38 (2009); 10.1116/1.3246406

Photoluminescence from Er-doped Si-rich Si oxides deposited by magnetron sputtering in $\mathrm{Ar}$ or $\mathrm{Ar}+\mathrm{H} 2$ plasmas J. Vac. Sci. Technol. A 27, 101 (2009); 10.1116/1.3043465

Effect of ion-irradiation induced defects on the nanocluster $\mathrm{Si} / \mathrm{Er} 3+$ coupling in Er-doped silicon-rich silicon oxide

Appl. Phys. Lett. 91, 021909 (2007); 10.1063/1.2752538

Sub-nanometric metallic Au clusters as efficient Er 3 + sensitizers in silica

Appl. Phys. Lett. 89, 151121 (2006); 10.1063/1.2266229

The $1.54-\mu \mathrm{m}$ photoluminescence from an ( $\mathrm{Er}, \mathrm{Ge})$ co-doped Si O 2 film deposited on Si by rf magnetron sputtering

Appl. Phys. Lett. 85, 4475 (2004); 10.1063/1.1819514

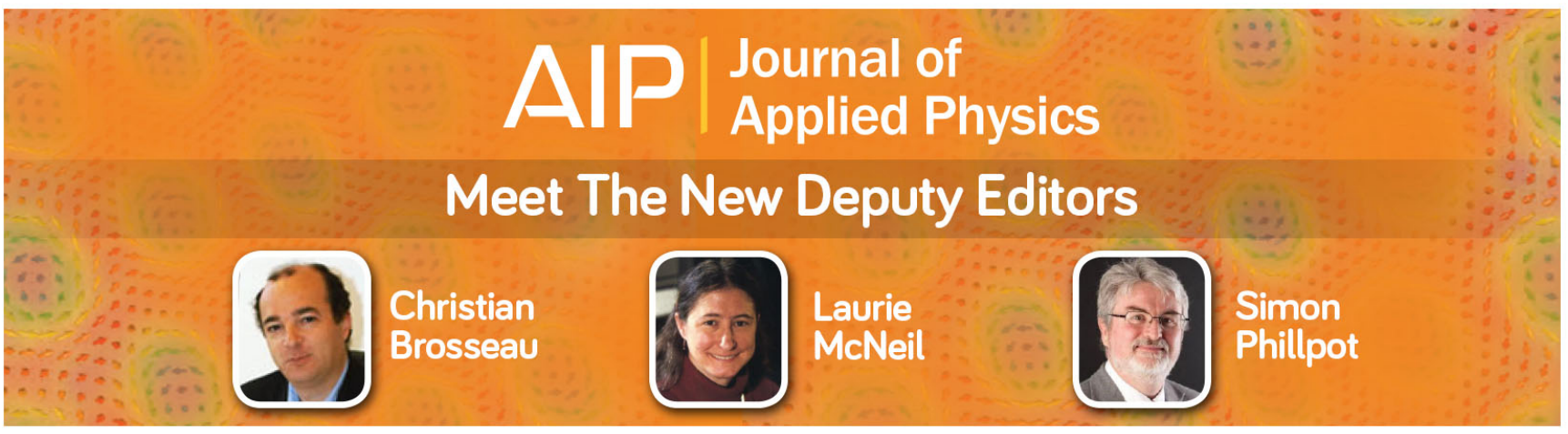




\title{
Efficient energy transfer from Si-nanoclusters to Er ions in silica induced by substrate heating during deposition
}

\author{
Sébastien Cueff, ${ }^{1}$ Christophe Labbé ${ }^{1,},{ }^{1, a)}$ Julien Cardin, ${ }^{1}$ Jean-Louis Doualan, ${ }^{1}$ \\ Larysa Khomenkova, ${ }^{1}$ Khalil Hijazi, ${ }^{1}$ Olivier Jambois, ${ }^{2}$ Blas Garrido, ${ }^{2}$ and Richard Rizk ${ }^{1}$ \\ ${ }^{1}$ Centre de Recherche sur les Ions, les Matériaux et la Photonique (CIMAP), ENSICAEN, CNRS, \\ CEA/IRAMIS, Université de Caen, 14050 CAEN Cedex, France \\ ${ }^{2}$ Dept. Electrònica, MIND-IN2UB, Universitat de Barcelona, Martí i Fanquès 1, 08028 Barcelona, CAT, \\ Spain
}

(Received 14 May 2010; accepted 22 July 2010; published online 17 September 2010)

\begin{abstract}
This study investigates the influence of the deposition temperature $T_{\mathrm{d}}$ on the Si-mediated excitation of Er ions within silicon-rich silicon oxide layers obtained by magnetron cosputtering. For $T_{\mathrm{d}}$ exceeding $200{ }^{\circ} \mathrm{C}$, an efficient indirect excitation of $\mathrm{Er}$ ions is observed for all as-deposited samples. The photoluminescence intensity improves gradually up to a maximum at $T_{\mathrm{d}}=600{ }^{\circ} \mathrm{C}$ before decreasing for higher $T_{\mathrm{d}}$ values. The effects of this "growth-induced annealing" are compared to those resulting from the same thermal budget used for the "classical" approach of postdeposition annealing performed after a room temperature deposition. It is demonstrated that the former approach is highly beneficial, not only in terms of saving time but also in the fourfold enhancement of the Er photoluminescence efficiency. (c) 2010 American Institute of Physics. [doi:10.1063/1.3481375]
\end{abstract}

\section{INTRODUCTION}

Silicon-rich silicon oxide matrix doped with $\mathrm{Er}^{3+}$ ions (SRSO:Er) is now a well-known material investigated for Si-based photonics. ${ }^{1}$ This system can take advantage of the energy transfer from Si-nanoclusters (Si-nc) to erbium ions and then benefits from the high absorption cross section of Si-nc, which is nearly three orders of magnitude higher than the direct excitation cross section of Er ions. ${ }^{2,3}$ Such a material should, therefore, allow the fabrication of low-cost and silicon-compatible photonic devices (LEDs, planar optical amplifiers, laser, etc.). To achieve an amplifying medium, the coupling between Si-nc and Er ions must ensure the population inversion, and this requires in turn a careful optimization of the material. The fabrication process appears, therefore, as a crucial step regarding the distance-dependent interactions between the $\mathrm{Er}^{3+}$ ions and the Si-based sensitizers. ${ }^{4-8}$ It is then essential to nanoengineer the density and distribution of both $\mathrm{Er}^{3+}$ ions and Si-based sensitizers within the silica matrix. In this regard, several groups have analyzed the influence of different annealing treatments on the optical performance of SRSO:Er layers ${ }^{9-13}$ usually deposited at room temperature (RT) before being subsequently annealed at different temperatures. Such a process allowed the formation of Si-nc sensitizers and then the observation of Er photoluminescence (PL) under nonresonant optical excitation. However, our group has recently observed an Er-PL under these indirect excitation conditions on the as-deposited samples at about $500{ }^{\circ} \mathrm{C} .{ }^{13,14}$ The Er emission was improved after annealing at about $500-600{ }^{\circ} \mathrm{C}$, and this aspect was also confirmed by another team on similarly sputtered layers. ${ }^{15} \mathrm{We}$ have assigned such an observation to the formation of $\mathrm{Si}$ based sensitizers during the deposition process that are ex-

${ }^{a)}$ Electronic mail: christophe.labbe@ensicaen.fr. pected to be very small and dense, ensuring a noticeable coupling with the Er ions. Nevertheless, a careful and systematic examination of the influence of the deposition temperature $\left(T_{\mathrm{d}}\right)$ on SRSO:Er thin films is still lacking. In the present study, we demonstrate that the deposition temperature governs, on the one hand, the formation of Si-sensitizers in the as-deposited layers, and influences, on the other hand, the composition and density of sensitized Er ions. The relevance of such a "growth-induced annealing" is further evidenced through a comparison with a standard postdeposition annealing bringing into operation the same thermal budget.

\section{EXPERIMENTAL DETAILS}

Series of SRSO:Er samples were deposited onto a p-type, 250- $\mu \mathrm{m}$-thick silicon wafer, thanks to the magnetron cosputtering of three confocal cathodes $\left(\mathrm{SiO}_{2}, \mathrm{Si}\right.$, and $\left.\mathrm{Er}_{2} \mathrm{O}_{3}\right)$ under a plasma of pure Argon at a pressure of 2 mTorr. The deposition temperature $\left(T_{\mathrm{d}}\right)$ was varied from RT to $700{ }^{\circ} \mathrm{C}$, being the maximal temperature that can be applied. The duration of all depositions were set to two hours. The power densities applied on the three confocals targets $\mathrm{P}_{\mathrm{SiO}_{2}}$ $\approx 8.88 \mathrm{~W} / \mathrm{cm}^{2}, \quad \mathrm{P}_{\mathrm{Si}} \approx 1.63 \mathrm{~W} / \mathrm{cm}^{2}, \quad \mathrm{P}_{\mathrm{Er}_{2} \mathrm{O}_{3}} \approx 0.44 \mathrm{~W} / \mathrm{cm}^{2}$ were kept constant for all depositions.

The Er content was measured by time-of-flight secondary ion mass spectroscopy (TOF-SIMS) measurements. This TOF-SIMS technique was calibrated by a reference SRSO:Er sample in which the Er concentration was accurately measured by Rutherford backscattering. surfaces of deposited layers were analyzed by atomic force microscope (AFM) provided by Digital Instruments (Nanoscope), operating in tapping mode at RT. The Si excess was estimated by a Fourier transform infrared (FTIR) spectroscopy approach detailed elsewhere. ${ }^{14}$ The refractive index and the thickness were measured using spectroscopic ellipsometry (SE). 


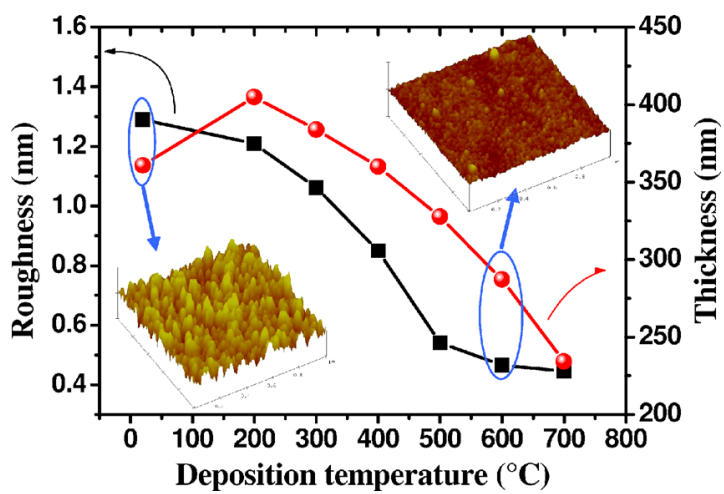

FIG. 1. (Color online) rms roughness measured by AFM and layer thickness measured by $\mathrm{SE}$ as a function of deposition temperature $T_{\mathrm{d}}$. Two typical AFM micrographs (scan area: $1 \mu \mathrm{m}^{2}$ ) are also shown for the depositions at RT and at $600{ }^{\circ} \mathrm{C}$.

Visible and IR PL spectra were obtained using the 476 $\mathrm{nm}$ excitation wavelength from an $\mathrm{Ar}^{+}$laser which is a nonresonant wavelength for the erbium ion. The spot size of the laser beam was measured by a "moving knife-edge" method and was found to be around $1 \mathrm{~mm}$ at $1 / \mathrm{e}^{2}$ of the maximum intensity. A $1 \mathrm{~m}$ single grating monochromator (Jobin Yvon) and a liquid-nitrogen-cooled germanium detector (Northcoast) were used to collect the Er-PL while the visible spectra were collected with a photomultiplier tube. These measurements were made by using the standard lock-in techniques (SP830 DPS) referenced with a chopping frequency of $9 \mathrm{~Hz}$. Time-resolved measurements were obtained by the $435 \mathrm{~nm}$ excitation wavelength of a pulsed Optical Parametric Oscillator (OPO). The pulse duration was $\sim 5 \mathrm{~ns}$ and the spot size $0.8 \mathrm{~mm}$ at $1 / \mathrm{e}^{2}$ of the maximum intensity. The PL signal of the time-resolved measurements was collected by an InGaAs detector.

\section{RESULTS AND DISCUSSION}

\section{A. Structural analyses}

The deposition temperature $T_{\mathrm{d}}$ is expected to have an influence on several structural parameters. We have first analyzed the evolution of the surface quality of the deposited layers by AFM techniques. Figure 1 shows the variation in the surface roughness in terms of root mean square (rms) as a function of $T_{\mathrm{d}}$, as well as two typical AFM images for two $T_{\mathrm{d}}$ values (RT and $600{ }^{\circ} \mathrm{C}$ ). The roughness (rms) continuously softens from 1.6 to $0.3 \mathrm{~nm}$ when $T_{\mathrm{d}}$ increases, with a steep decrease for $T_{\mathrm{d}}$ between 300 and $600{ }^{\circ} \mathrm{C}$.

A similar behavior is observed for the thickness (Fig. 1) which also decreases with $T_{\mathrm{d}}$, from about 380 to $240 \mathrm{~nm}$, i.e., a reduction in about $35 \%$. The surface roughness is generally correlated with both mobility and growth rate of the deposited atoms, especially in this specific layer-by-layer deposition technique. Indeed, the surface roughness reflects some balance between the deposition rate and the surface mobility of the sticking elements. For example, a high surface roughness is expected to result, either from a limited surface mobility at a given sputtering rate, or from a high surface mobility at a faster sputtering rate. Besides, a high surface mobility should lead to a progressive relaxation of the net-

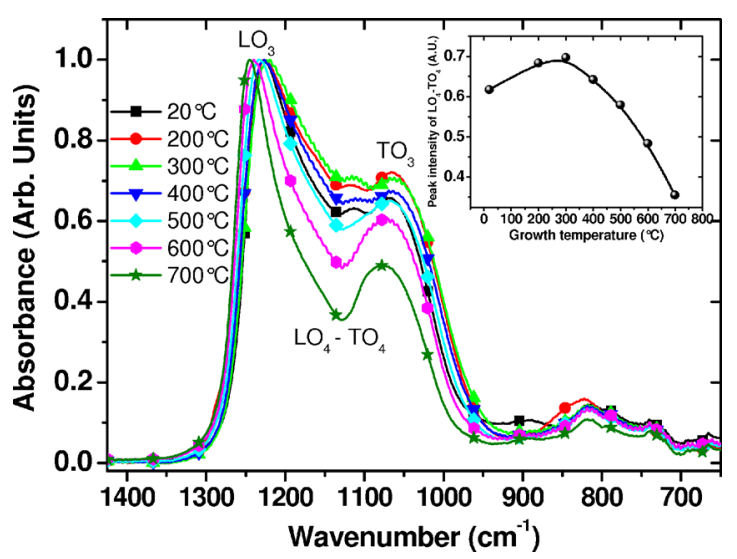

FIG. 2. (Color online) Infrared absorption spectra normalized for asdeposited samples, collected at Brewster angle $\left(65^{\circ}\right)$. Inset: relative evolution of $\mathrm{LO}_{4}-\mathrm{TO}_{4}$ peaks intensity according to the deposition temperature $T_{\mathrm{d}}$.

work through lower distortion of the atomic bond angles and an improved atomic rearrangement, together with better compactness. Thus, the decrease in both thickness and roughness can be explained by the increasing surface mobility of the deposited elements when $T_{\mathrm{d}}$ is increased. This latter statement would be further confirmed by a concomitant decrease in the atomic disorder within the film material. We have collected the FTIR spectra on the various films, in order to examine the evolution of the so-called $\mathrm{LO}_{4}-\mathrm{TO}_{4}$ doublet that is known to be indicative of the disorder within the $\mathrm{SiO}_{2}$ matrix. $^{16}$

Figure 2 compares the corresponding FTIR spectra obtained at the Brewster incidence angle $\left(65^{\circ}\right)$ after being normalized on the $\mathrm{LO}_{3}$ peak. One can observe that the intensity and structure of $\mathrm{LO}_{4}-\mathrm{TO}_{4}$ doublet are slightly affected when $T_{\mathrm{d}}$ increases from RT to $400{ }^{\circ} \mathrm{C}$. However, a gradual and significant decrease in the intensity is observed for $T_{\mathrm{d}}$ $>400{ }^{\circ} \mathrm{C}$, hence allowing an increasingly better separation between the $\mathrm{LO}_{3}$ and $\mathrm{TO}_{3}$ peaks. This decrease demonstrates that a strong reduction in the disorder occurs within the $\mathrm{SiO}_{2}$ matrix when $T_{\mathrm{d}}$ increases up to $700{ }^{\circ} \mathrm{C}$. Such a phenomenon confirms the above-mentioned increasing mobility of the deposited elements. This leads, therefore, to the following straightforward conclusion: the higher is the deposition temperature, the better is the atomic arrangement within the matrix.

An optimum reduction in the disorder should result in an improvement of the compactness, together with a more relaxed network. However, such suggestions explain only partly the decrease in the thickness of the deposited films. Indeed, the expected improvement of the compactness, combined to the reduction in the structural disorder, is not sufficient to explain the $35 \%$ decrease in the thickness. A significant part of this thickness lowering may be due to a temperature-dependent sticking/desorption rate of the sputtered elements, already demonstrated for elemental oxygen on Si substrate, ${ }^{17}$ and/or the creation of volatiles species. Thus, the composition of the thin film may change according to the deposition temperature. The concentrations of the deposited elements and especially those of the silicon excess and Er ions are important parameters that must be determined. 


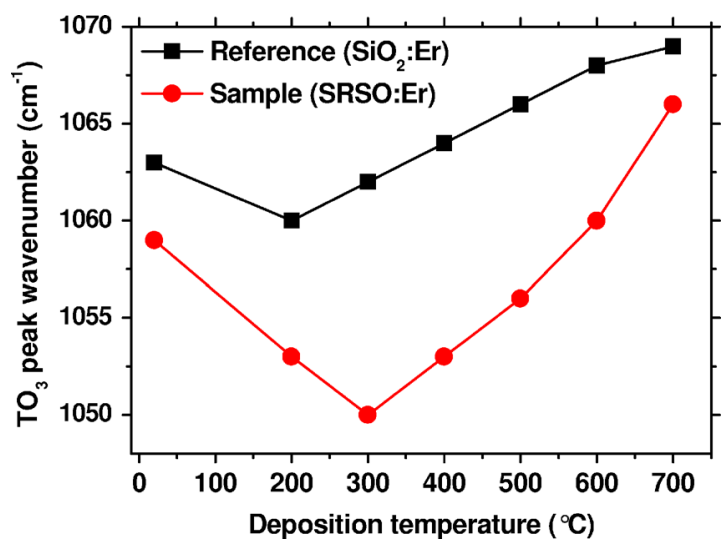

FIG. 3. (Color online) Evolution of the wave number of $\mathrm{SiO}_{2}$ : Er references and SRSO:Er samples for each deposition temperature.

The silicon excess is defined here as the percentage of elemental silicon present inside the sample in addition to the proportion of $\mathrm{Si}$ in stoichiometric $\mathrm{SiO}_{2}$. For the as-deposited SRSO:Er thin films, the estimate of the Si excess is not straightforward, considering that the transmission electronic microscopy (TEM) observations are unable to detect either the formation of Si-nc or their evolution with $T_{\mathrm{d}}$. This is due to the lack of contrast between the amorphous $\mathrm{Si}$-nc and the silica matrix, as stated by previous studies. ${ }^{9,18}$ Moreover, the smallness of Si-nc in our as-deposited films makes difficult their observation by energy filtered TEM approach. ${ }^{18}$ Nevertheless, a rough estimate of the $\mathrm{Si}$ excess content is possible from the analysis of the $\mathrm{TO}_{3}$-peak energy shift evolution in the FTIR spectra of our SRSO:Er film, as described elsewhere ${ }^{19}$ and adopted in our previous work. ${ }^{14}$ However, the above-described atomic disorder induces some shift in the $\mathrm{TO}_{3}$ peak that can be misinterpreted as being due to some $\mathrm{Si}$ excess. To overcome this issue, a reference $\mathrm{SiO}_{2}$ sample doped with Er was deposited for each $T_{\mathrm{d}}$ value. Such a reference sample is considered as free from silicon excess and its $\mathrm{TO}_{3}$ peak is compared to that of the SRSO:Er sample deposited at the same $T_{\mathrm{d}}$ (see Fig. 3).

It can be seen in Fig. 3 that for both SRSO:Er sample and $\mathrm{SiO}_{2}: \mathrm{Er}$ reference, the $\mathrm{TO}_{3}$ peak position decreases when $T_{\mathrm{d}}$ changes from RT to $300{ }^{\circ} \mathrm{C}\left(200{ }^{\circ} \mathrm{C}\right.$ for the reference), then increases for higher values of $T_{\mathrm{d}}$. The evolution of the $\mathrm{TO}_{3}$ peak for the $\mathrm{SiO}_{2}$ : Er reference is considered as reflecting an evolution of the atomic arrangement rather than any $\mathrm{Si}$ excess. On the basis of these considerations, the $\mathrm{Si}$ excess in the SRSO layer has been estimated from the following linear relation:

$$
\% \mathrm{Si}_{\text {excess }}=\frac{v_{\mathrm{TO}_{3}}^{\mathrm{ref} \mathrm{SiO}_{2}}-v_{\mathrm{TO}}^{\mathrm{SRSO}: \mathrm{Er}}}{v_{\mathrm{TO}_{3}}^{\text {ref } \mathrm{SiO}_{2}}-v_{\mathrm{TO}_{3}}^{\mathrm{Si}}} \times 100,
$$

where $v_{\mathrm{TO}}^{\text {ref } \mathrm{SiO}_{2}}$ and $\nu_{\mathrm{TO}}^{\mathrm{SRSO}} \mathrm{Er}$ are, respectively, the $\mathrm{TO}_{3}$ peak wavenumbers of $\mathrm{SiO}_{2}: \mathrm{Er}$ and SRSO:Er, while $v_{\mathrm{TO}_{3}}^{\mathrm{Si}}$ is the $\mathrm{TO}_{3}$ peak wavenumber of $\mathrm{Si}$ taken constant for all $T_{\mathrm{d}}$ $\left(960 \mathrm{~cm}^{-1}\right)$.

This approach allowed us to subtract the "background disorder" of the sputtered $\mathrm{SiO}_{2}: \mathrm{Er}$ and hence determine the corresponding $\mathrm{Si}$ excess for SRSO:Er. To note that the FTIR

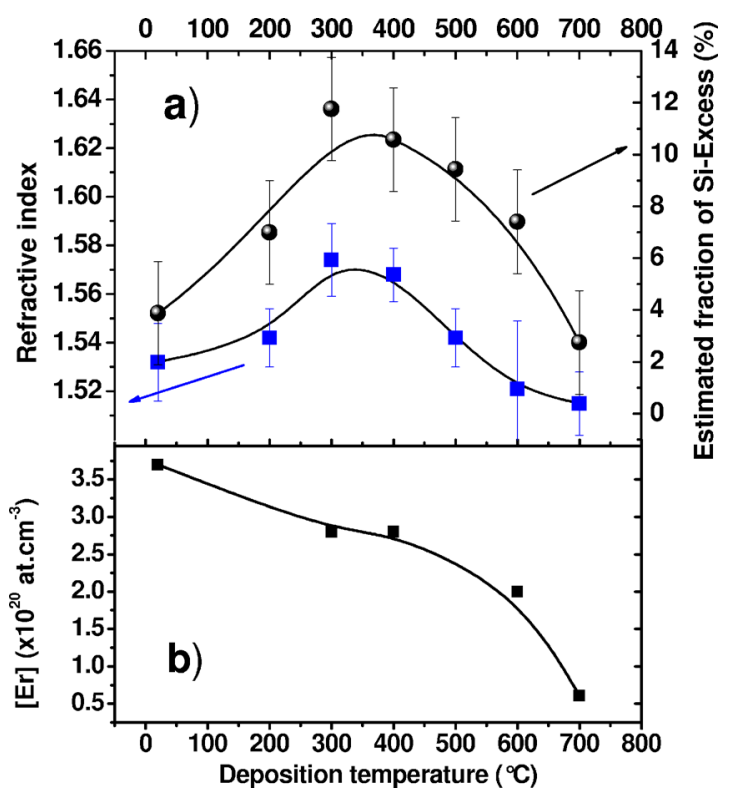

FIG. 4. (Color online) (a) Ellipsometry measurements of the refractive index at $633 \mathrm{~nm}$ and Si excess as estimated by FTIR techniques and the formula (1) in function of $T_{\mathrm{d}}$ (the curves are just a guide for the eyes). (b) SIMS measurements of the erbium concentration according to the deposition temperature.

approach underestimates the amount of $\mathrm{Si}$ excess because the $\mathrm{Si}-\mathrm{Si}$ links within the $\mathrm{Si}-\mathrm{nc}$ formed during the growth are not detected and then not taken into account. Nevertheless, regardless of the absolute value of Si excess, their evolution is considered as reliably described by the FTIR-related estimate, as attested by an earlier comparison with our X-ray Photoelectron Spectroscopy (XPS) analyses done on similar samples. $^{20}$

Figure 4(a) displays the evolution of the Si excess, as estimated from Eq. (1), in function of $T_{\mathrm{d}}$. A first increase in Si excess is observed when $T_{\mathrm{d}}$ is raised from RT to $300{ }^{\circ} \mathrm{C}$, which indicates that the deposition of $\mathrm{Si}$ is favored by the rise of $T_{\mathrm{d}}$ up to $300{ }^{\circ} \mathrm{C}$. This increase is followed by a "symmetric" decrease for higher $T_{\mathrm{d}}$ values. This behavior of $\mathrm{Si}$ excess is consistent with a similar evolution of the refractive index, $n$, as determined by SE measurements. To note that $n$ of the $\mathrm{SiO}_{2}$ : Er references remains almost constant for all $T_{\mathrm{d}}$ at about 1.46 (not shown), i.e., very close to that of stoichiometric $\mathrm{SiO}_{2}$ (1.45). This corroborates the assignment of the evolution of $n$ for SRSO:Er samples to that of the Si excess. In particular, the decrease in $n$ for $T_{\mathrm{d}}>300{ }^{\circ} \mathrm{C}$, concomitant to a decrease in $\mathrm{Si}$ excess as estimated by FTIR, reflects an effective lowering of the $\mathrm{Si}$ excess. Thus, the estimated decrease in $\mathrm{Si}$ excess is not only due to an increasing underestimate originated from further and further formation of Si-nc. In this regards, the $\mathrm{Si}$ excess lowering can be provoked by some increasing interactions/reactions between the deposited species, inducing the formation of volatile elements such as $\mathrm{SiO}$ for $T_{\mathrm{d}} \geq 300{ }^{\circ} \mathrm{C}$, as supported by earlier studies. ${ }^{21-23}$ Such processes are temperature-dependent, and $T_{\mathrm{d}}$ can have also some influence on the concentration $\mathrm{N}_{\mathrm{Er}}$ of incorporated Er. Indeed, $\mathrm{N}_{\mathrm{Er}}$ was found to decrease gradually from 3.7 $\times 10^{20}$ atom cm $\mathrm{cm}^{-3}$ to $6.1 \times 10^{19}$ atom $\mathrm{cm}^{-3}$ when $T_{\mathrm{d}}$ increases from RT to $700{ }^{\circ} \mathrm{C}$ [see Fig. 4(b)]. The origin of this 


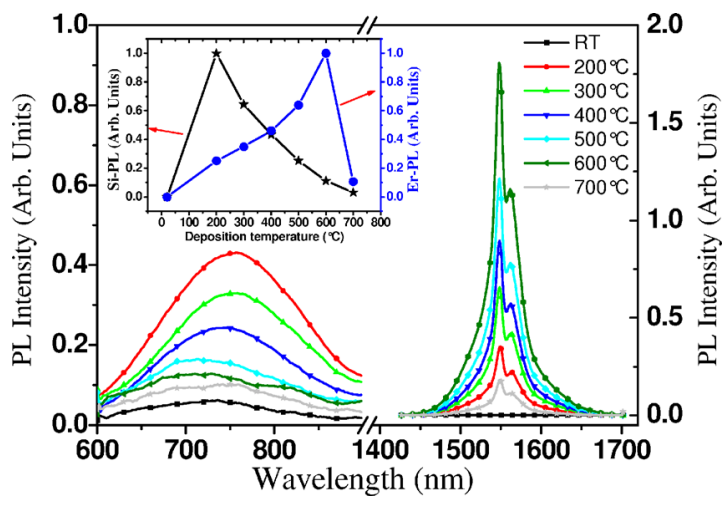

FIG. 5. (Color online) PL spectra (normalized to the thickness) at a flux of $5 \times 10^{18}$ photons $\mathrm{cm}^{2} / \mathrm{s}$ of both Si-nc (range $600-900 \mathrm{~nm}$ ) and of $\mathrm{Er}^{3+}$ ions (range 1400-1700 nm) for all deposition temperatures. Inset: Si-nc PL intensities compared to the Er-PL intensities according to the deposition temperature (both normalized to unity).

gradual decrease is difficult to identify but might be correlated with the increasing reactive character of the sticking mechanism of the sputtered elements when $T_{\mathrm{d}}$ is increased.

\section{B. PL properties}

Figure 5 shows the evolution of the PL spectra recorded on all samples along two main wavelength ranges: the Si-PL feature from 600 to $900 \mathrm{~nm}$ range and the Er-PL contribution around $1540 \mathrm{~nm}$. This latter corresponds to the ${ }^{4} I_{13 / 2}$ $\rightarrow{ }^{4} I_{15 / 2} \mathrm{Er}^{3+}$ transition. The visible emission that peaks at $750 \mathrm{~nm}$ for $T_{\mathrm{d}}=200{ }^{\circ} \mathrm{C}$ gradually shifts toward $720 \mathrm{~nm}$ when $T_{\mathrm{d}}$ is increased to $600-700{ }^{\circ} \mathrm{C}$. This visible emission is assigned to quantum confinement within Si-nc (Ref. 24) that do not transfer their energy to $\mathrm{Er}^{3+}$ ions. ${ }^{3,25}$ The slight shift to higher energies, in spite of $T_{\mathrm{d}}$ increase, reflects some lowering in the average size of Si-nc which is quite compatible with the above-commented decrease in Si excess. It is also worth noting that this visible emission was similarly observed and attributed to Si-nc by Savchyn et al. ${ }^{9,26,27}$ for their samples annealed at $1000{ }^{\circ} \mathrm{C}$ during only $100 \mathrm{~s}$. On the contrary, no contribution is detected in our samples of the so-called luminescent centers (LCs) emitting at around 500 nm. ${ }^{9}$

The presence of a significant Er-PL in our as-deposited samples (for $T_{\mathrm{d}} \geq 200{ }^{\circ} \mathrm{C}$ ) excited with a nonresonant wavelength reveals the occurrence of an efficient energy transfer from Si-nc to $\mathrm{Er}^{3+}$. When $T_{\mathrm{d}}$ is raised from 200 to $600{ }^{\circ} \mathrm{C}$, the Er-PL shows a systematic increase at the expense of the Si-nc-PL, hence indicating an increase in sensitized Er ions (see inset of Fig. 2) through Si-nc sensitizers. The sample deposited at RT is suspected to be free from Si-sensitizers, since no Er-PL is detected. Such sensitizers start apparently to form when $T_{\mathrm{d}}$ reaches and exceeds $200{ }^{\circ} \mathrm{C}$. It is worth noting that the Er-PL intensity increases by a factor of almost 5 , in spite of the $\mathrm{N}_{\mathrm{Er}}$ lowering, when $T_{\mathrm{d}}$ is increased from 200 to $600{ }^{\circ} \mathrm{C}$, before showing an abrupt decrease for $T_{\mathrm{d}}$ $=700{ }^{\circ} \mathrm{C}$ [Fig. 4(b)]. The increase in $T_{\mathrm{d}}$ improves also the quality of the matrix, as demonstrated by the systematic increase in the Er emission lifetime, for the longer time decay, from $\sim 1 \mathrm{~ms}$ at $200{ }^{\circ} \mathrm{C}$ to $2.5 \mathrm{~ms}$ at $700{ }^{\circ} \mathrm{C}$, (Fig. 6) which

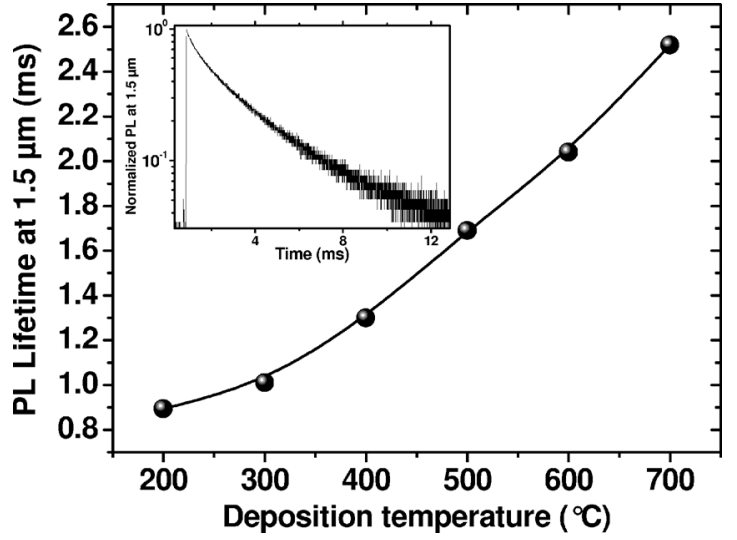

FIG. 6. Behavior of the lifetime values of $\mathrm{Er}^{3+}$ at $1.53 \mu \mathrm{m}$ according to the deposited temperature detectable at the lower excitation photon flux. Inset: a typical PL decay trace of SRSO:Er collected for sample deposited at $600{ }^{\circ} \mathrm{C}$. Note the PL decay dynamics is biexponential as described in Ref. 28.

is almost one order of magnitude higher than the lifetime reported for similar layers containing LCs. ${ }^{9,26}$

The increase in the Er-PL intensity with $T_{\mathrm{d}}$ may originate from the formation of small Si-sensitizers, as already mentioned, and also from the improvement of the environment of $\mathrm{Er}^{3+}$ ions which is expected to increase the number of optically active $\mathrm{Er}^{3+}$ ions. Indeed, under the resonant wavelength of $980 \mathrm{~nm}$ corresponding to a resonant direct excitation of Er (i.e., without the Si-nc relays) from the ground state ${ }^{4} I_{15 / 2}$ to the second excited level ${ }^{4} I_{11 / 2}$, the Er-PL increases systematically up to $T_{\mathrm{d}}=600{ }^{\circ} \mathrm{C}$ (see Fig. 7), reflecting a concomitant enhancement of the number of the optically active ions. On the other hand, the sudden abrupt decrease in the $\mathrm{Er} \mathrm{PL}$ at $700{ }^{\circ} \mathrm{C}$ for both nonresonant 476 $\mathrm{nm}$ and resonant $980 \mathrm{~nm}$ excitation lines, suggests some agglomeration of the Er ions at this deposition temperature $\left(700{ }^{\circ} \mathrm{C}\right)$, which reduces the number of optically active $\mathrm{Er}$ ions, ${ }^{29}$ and consequently the PL intensity.

The deposition temperature thus governs three different phenomena occurring during the growth process: (i) the formation and growth of Si-based sensitizers, (ii) the variation in both Si excess and Er content, and (iii) the improvement

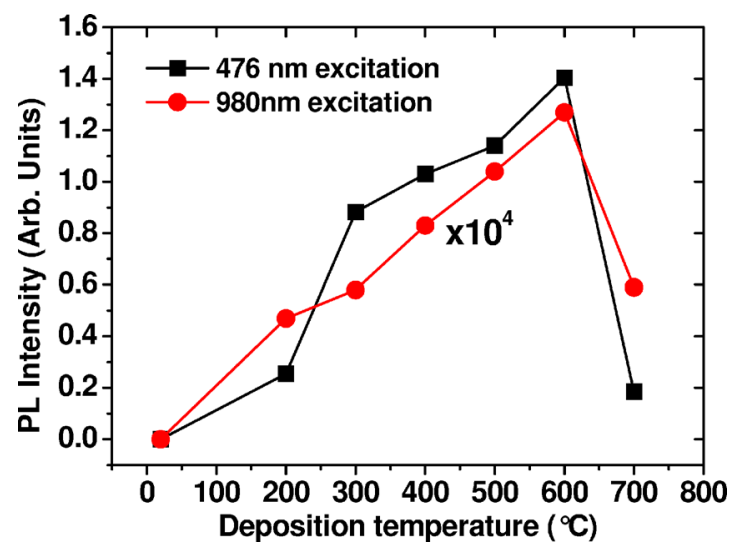

FIG. 7. (Color online) Comparison of PL intensity of as-deposited samples recorded at $1.53 \mu \mathrm{m}$ and obtained after indirect excitation $(476 \mathrm{~nm})$ and direct excitation $(980 \mathrm{~nm})$. Note that the results corresponding to the $980 \mathrm{~nm}$ excitation are multiplied by $10^{4}$. 


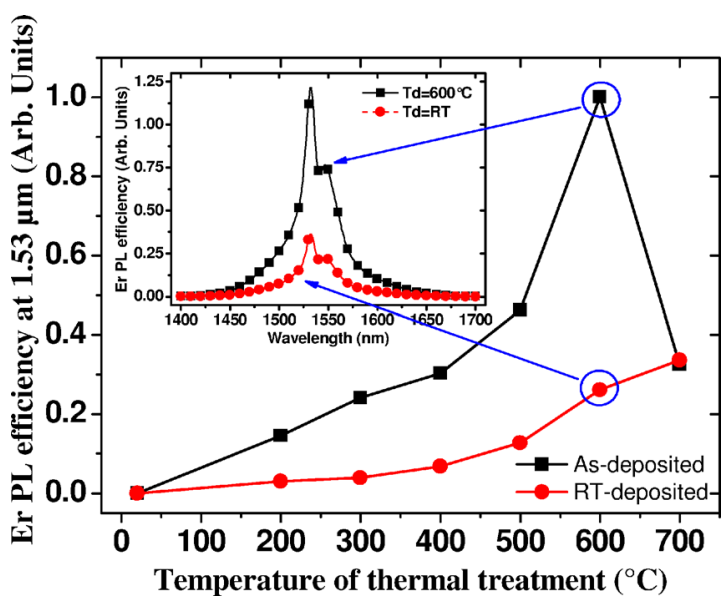

FIG. 8. (Color online) Comparison of the evolution of the Er-PL efficiency of the as-deposited samples to that obtained from their counterparts deposited at RT and annealed for $2 \mathrm{~h}$ at $T=T_{\mathrm{d}}$. The inset compares two normalized Er-PL efficiency spectra of two SRSO: Er thin films: (i) deposited at $600{ }^{\circ} \mathrm{C}$ for $2 \mathrm{~h}$ (full squares) and (ii) deposited at RT and annealed at $600{ }^{\circ} \mathrm{C}$ for 2 $\mathrm{h}$ (full circles).

of the quality of the matrix as demonstrated by the decrease in atomic disorder and the increase in the Er emission lifetime. Those concomitant effects lead to a positive paradox when the deposition temperature is raised from 200 to $600{ }^{\circ} \mathrm{C}$ : the PL of $\mathrm{Er}^{3+}$ still increases whereas both the $\mathrm{Si}$ excess and the Er concentration get lower. Indeed, the improvement of the Er-PL up to a maximum for $T_{\mathrm{d}}=600{ }^{\circ} \mathrm{C}$ corresponds to a moderate value of $\mathrm{Si}$ excess and almost the lowest $\mathrm{N}_{\mathrm{Er}}$. Such an improvement of the PL intensity is, therefore, arising from the influence of the deposition temperature on the growth mechanisms. This leads to some optimum density and distribution of both sensitizers and $\mathrm{Er}$ ions, resulting in better luminescence of $\mathrm{Er}^{3+}$ for the used growth parameters. Two relevant parameters also compete for this enhancement: the number of optically active $\mathrm{Er}^{3+}$ ions which evolves similarly against $T_{\mathrm{d}}$ (Fig. 7) and the reduction in nonradiative recombination, as attested by the raise of the lifetime by a factor of $\sim 3$ (Fig. 6).

To give further insight on the influence of the growthinduced annealing, we compare the optical emission of each as-deposited sample grown at a given $T_{\mathrm{d}}$ to that recorded from its counterpart film deposited at RT and then annealed for $2 \mathrm{~h}$ (i.e., equivalent to the deposition duration) at $T=T_{\mathrm{d}}$. This approach allows one to compare the samples having been submitted to the same "thermal budget," either during deposition or after deposition. The main difference between the intrinsically heated samples during the deposition process and those annealed after RT deposition, lies in the composition evolution: for the former, both $\mathrm{N}_{\mathrm{Er}}$ value and $\mathrm{Si}$ excess are varying with $T_{\mathrm{d}}$, whereas these concentrations remain constant for the latter. To take into account this aspect and accurately compare the two kinds of samples, we define the Er-PL efficiency as the ratio $I_{\mathrm{PL}}^{\mathrm{Er}} / \mathrm{N}_{\mathrm{Er}}$, depending on $T_{\mathrm{d}}$. Figure 8 compares the Er-PL efficiency according to the temperature of thermal treatment, for both as-deposited and postdeposition annealed samples. For the as-deposited films, the Er-PL efficiency increases by a factor of 6-7 when $T_{\mathrm{d}}$ raises from 200 to $600{ }^{\circ} \mathrm{C}$. When compared to their counterparts annealed after RT deposition, their Er-PL efficiency is systematically higher by a factor that reaches a maximum of about 4 for $T_{\mathrm{d}}=600{ }^{\circ} \mathrm{C}$ (see inset).

This result demonstrates the relevance of layer deposited at a temperature as high as $600{ }^{\circ} \mathrm{C}$ which favors the surface mobility of the sticking elements that can diffuse with relatively low activation energy. By comparison, the volume diffusion of the elements occurring during the postdeposition annealing requires higher activation energy and result apparently in the formation of much less Si-based sensitizers and optically active $\mathrm{Er}^{3+}$ ions. One can therefore infer that the growth-induced annealing is not only a "time-saving" approach but it is also a way to enhance the optical performance of SRSO:Er thin films. On the other hand, the matrix of the as-deposited samples could be further improved by an additional postdeposition annealing treatment which can be the object of a specific work beyond the scope of this study.

\section{CONCLUSION}

In conclusion, the influence of the deposition temperature on the optical properties of SRSO:Er thin films was carefully investigated. The concentration of $\mathrm{Er}^{3+}$ ions and the amount of $\mathrm{Si}$ excess were found to change with the deposition temperature. It was also demonstrated that an efficient energy transfer from Si-nc to $\mathrm{Er}^{3+}$ can be obtained for asdeposited samples at a deposition temperature exceeding $200{ }^{\circ} \mathrm{C}$, without any annealing. When the deposition temperature is further raised to $600{ }^{\circ} \mathrm{C}$, the Er-PL efficiency is enhanced by a factor of $6-7$, compared to $200{ }^{\circ} \mathrm{C}$, originating from optimum density and distribution of both Sisensitizers and optically active Er ions, as well as from the matrix improvement. The emission lifetime shows a consistent improvement with $T_{\mathrm{d}}$, up to about $2.5 \mathrm{~ms}$. For comparable thermal budget, the growth-induced annealing at $T_{\mathrm{d}}$ $=600{ }^{\circ} \mathrm{C}$ was found to favor the Er-PL efficiency by a factor of about 4 , in comparison with the classical annealing performed on layer deposited at RT.

${ }^{1}$ L. Pavesi and D. J. Lockwood, Top. Appl. Phys. 94, 1 (2004).

${ }^{2}$ A. J. Kenyon, P. F. Trwoga, M. Federighi, and C. W. Pitt, J. Phys.: Condens. Matter 6, L319 (1994).

${ }^{3}$ M. Fujii, M. Yoshida, Y. Kanzawa, S. Hayashi, and K. Yamamoto, Appl. Phys. Lett. 71, 1198 (1997).

${ }^{4}$ J. H. Jhe, J. H. Shin, K. J. Kim, and D. W. Moon, Appl. Phys. Lett. 82, 4489 (2003)

${ }^{5}$ B. Garrido, C. Garcia, P. Pellegrino, D. Navarro-Urrios, N. Daldosso, L. Pavesi, F. Gourbilleau, and R. Rizk, Appl. Phys. Lett. 89, 163103 (2006).

${ }^{6}$ F. Gourbilleau, C. Dufour, R. Madelon, and R. Rizk, J. Lumin. 126, 581 (2007).

${ }^{7}$ K. Choy, F. Lenz, X. X. Liang, F. Marsiglio, and A. Meldrum, Appl. Phys. Lett. 93, 261109 (2008).

${ }^{8}$ F. Gourbilleau, M. Levalois, C. Dufour, J. Vicens, and R. Rizk, J. Appl. Phys. 95, 3717 (2004).

${ }^{9}$ O. Savchyn, F. R. Ruhge, P. G. Kik, R. M. Todi, K. R. Coffey, H. Nukala, and H. Heinrich, Phys. Rev. B 76, 195419 (2007).

${ }^{10}$ G. Wora Adeola, H. Rinnert, P. Miska, and M. Vergnat, J. Appl. Phys. 102, 053515 (2007)

${ }^{11}$ A. Kanjilal, L. Rebohle, M. Voelskow, W. Skorupa, and M. Helm, J. Appl. Phys. 104, 103522 (2008).

${ }^{12}$ A. R. Wilkinson and R. G. Elliman, J. Appl. Phys. 96, 4018 (2004).

${ }^{13}$ S. Cueff, C. Labbé, J. Cardin, and R. Rizk, IOP Conf. Ser.: Mater. Sci. Eng. 6, 012021 (2009).

${ }^{14}$ K. Hijazi, R. Rizk, J. Cardin, L. Khomenkova, and F. Gourbilleau, J. Appl. Phys. 106, 024311 (2009). 
${ }^{15}$ O. Savchyn, R. M. Todi, K. R. Coffey, L. K. Ono, B. R. Cuenya, and P. G. Kik, Appl. Phys. Lett. 95, 231109 (2009).

${ }^{16}$ T. Kirk, Phys. Rev. B 38, 1255 (1988).

${ }^{17}$ M. P. D'evelyn, M. M. Nelson, and T. Engel, Surf. Sci. 186, 75 (1987).

${ }^{18}$ G. Franzò, S. Boninelli, D. Pacifici, F. Priolo, F. Iacona, and C. Bongiorno, Appl. Phys. Lett. 82, 3871 (2003).

${ }^{19}$ P. G. Pai, S. S. Chao, Y. Takagi, and G. Lukovsky, J. Vac. Sci. Technol. A4, 689 (1986).

${ }^{20}$ S. Charvet, R. Madelon, F. Gourbilleau, and R. Rizk, J. Appl. Phys. 85, 4032 (1999).

${ }^{21}$ P. Wickboldt, H. M. Cheong, D. Pang, J. H. Chen, and W. Paul, Mater. Res. Soc. Symp. Proc. 358 (1995).

${ }^{22}$ Y. Takakuwa, M. Nihei, and N. Miyamoto, Jpn. J. Appl. Phys., Part 2 32, L480 (1993).
${ }^{23}$ D. Gautam, E. Koyanagi, and T. Uchino, J. Appl. Phys. 105, 073517 (2009).

${ }^{24}$ R. Lockwood, A. Hryciw, and A. Meldrum, Appl. Phys. Lett. 89, 263112 (2006).

${ }^{25}$ F. Priolo, G. Franzò, D. Pacifici, V. Vinciguerra, F. Iacona, and A. Irrera, J. Appl. Phys. 89, 264 (2001).

${ }^{26}$ O. Savchyn, R. M. Todi, K. R. Coffey, L. K. Ono, B. R. Cuenya, and P. G. Kik, Appl. Phys. Lett. 94, 241115 (2009).

${ }^{27}$ O. Savchyn, P. G. Kik, R. M. Todi, and K. R. Coffey, Phys. Rev. B 77, 205438 (2008).

${ }^{28}$ A. Al Choueiry, A. M. Jurdyc, B. Jacquier, F. Gourbilleau, and R. Rizk, J. Appl. Phys. 106, 053107 (2009).

${ }^{29}$ A. Polman, D. C. Jacobson, D. J. Eaglesham, F. C. Kistler, and J. M. Poate, J. Appl. Phys. 70, 3778 (1991). 